2 Research Square

\title{
Combined Phacoemulsification and Intravitreal anti-vascular endothelial growth factor(VEGF) versus Dexamethasone Implant in Diabetics with Coexisting Cataract and Centre-involving Diabetic Macular Edema
}

\section{SHILPA IN}

Sankara Nethralaya

Muna Bhende

Sankara Nethralaya

Rajiv Raman ( $\sim$ rajivpgraman@gmail.com )

Sankara Nethralaya https://orcid.org/0000-0001-5842-0233

Viswanathan Natarajan

Sankara Nethralaya

\section{Research Article}

Keywords: Phacoemulsification, CI-DME, AntiVEGF, Dexamethasone implant

Posted Date: March 3rd, 2022

DOI: https://doi.org/10.21203/rs.3.rs-1305257/v1

License: () (1) This work is licensed under a Creative Commons Attribution 4.0 International License. Read Full License 


\section{Abstract}

Purpose: To compare the anatomical and functional outcome in groups who underwent combined phacoemulsification with intravitreal anti-vascular endothelial growth factor (VEGF) versus combined phacoemulsification with intravitreal dexamethasone implant who had centre-involving diabetic macular edema (Cl-DME) with significant cataract.

Methods: Best-corrected visual acuity (BCVA) and central subfield thickness (CST) were retrospectively evaluated in both groups at baseline,1 month, 3 months and 6 months follow up period.

Results: Fifty six eyes were analysed, 36 in phacoemulsification with anti-VEGF group and 20 in phacoemulsification with dexamethasone implant group. BCVA showed improvement from baseline of log MAR $0.54 \pm 0.58$ to $0.49 \pm 0.57$ at 1 month in combined phacoemulsification with anti-VEGF group. Phacoemulsification with intravitreal dexamethasone implant showed baseline BCVA of $0.43 \pm 0.34$ and $0.55 \pm 0.44$ at 6 months follow up with not much of visual improvement due to the chronicity of the DME. Mean CST groups of less than $300 \mu \mathrm{m}, 300-600 \mu \mathrm{m}$ and more than $600 \mu \mathrm{m}$ disclosed comparable trends in both Anti-VEGF ( $p=0.005)$ and Dexamethasone group ( $p=0.018)$ from the baseline to the 6 month follow up period. $300-600 \mu m$ CST group showed no such statistical significance in either group whereas in the $\geq 600 \mu \mathrm{m}$ mean CST group, there was significant statistical difference only in the dexamethasone group with $\mathrm{p}$ value of 0.043

Conclusions: This study demonstrates that individuals with CI-DME with lower baseline CST values undergoing combined phacoemulsification with either intravitreal Anti-VEGF or dexamethasone implant shows similar anatomical and functional success at six months. Eyes with higher baseline CST had better anatomical response to dexamethasone implant.

\section{Key Message}

The CST reduction was higher with combined phacoemulsification and dexamethasone implantation than that of combined phacoemulsification and antiVEGF with higher baseline CST.

\section{Introduction}

Diabetes mellitus affects 285 million people worldwide ${ }^{[1]}$ and India accounts for 77 million people (2019). ${ }^{[2]}$ According to the International Diabetes Federation, this number is expected to increase by twofold to 578 million by $2030 .{ }^{[2]}$ Cataract is the most common preventable and avoidable cause of blindness which tends to occur at much earlier age in individuals with diabetes mellitus. ${ }^{[3]}$ Diabetic retinopathy and maculopathy progression after an uneventful phacoemulsification surgery has been a subject of debate. Many studies have reported an increased risk of progression, whereas few have reported that the progression represents the natural course of the disease. ${ }^{[4]}$

Intravitreal anti-vascular endothelial growth factors (VEGF) are the new standard of care in management of diabetic macular edema (DME) in both phakic and pseudophakic eyes. Protocol I subgroup analysis found that visual outcomes with intravitreal triamcinolone (IVTA) were similar to those who received intravitreal anti-VEGF in pseudophakic DME patients. ${ }^{[5]}$ Corbelli et al have shown that, intravitreal implantation of dexamethasone with cataract surgery provides long term anatomical and functional success by its dual action on inflammatory cytokines as well as the blood retinal barrier. ${ }^{[6]}$

However, the comparison of combined phacoemulsification (PE) with anti-VEGF versus phacoemulsification with dexamethasone implant has not been studied. The aim of the study is to compare the anatomical and functional outcome in groups who underwent phacoemulsification and Intraocular lens (IOL) implantation with anti-VEGF versus phacoemulsification and IOL implantation along with intravitreal dexamethasone implant in eyes with centre involving DME(CI-DME) and significant cataract.

\section{Material And Methods}

This is a retrospective analysis of Group1(Patients who had undergone combined phacoemulsification and IOL with intravitreal anti-VEGF) and Group 2 (Patients who had undergone combined phacoemulsification and IOL with intravitreal Dexamethasone implant) who met the inclusion and exclusion criteria between January 2015 to December 2019.The study was approved by the Institutional review board and adhered to the Declaration of Helsinki. Informed consent was obtained from all the study participants.

Inclusion criteria were age $\geq 18$ years with visually significant cataract diagnosed on a slit lamp according to Wisconsin cataract grading system, type 1 or type $2 \mathrm{DM}, \mathrm{Cl}-\mathrm{DME}$ [CI-DME was defined as retinal thickening above the threshold value in the central subfield (1 mm) of the macular grid. The threshold values were defined as the average machine-specific mean thickness from a normal cohort +2 standard deviation (SD)], non-proliferative diabetic retinopathy (NPDR) according to ETDRS criteria or inactive laser-treated proliferative diabetic retinopathy (PDR). Only those with minimum 6 month follow up after cataract surgery were included in the study.

Exclusion criteria were inability to provide informed consent, $\mathrm{HbA} 1 \mathrm{c}>9 \%$, other concurrent retinal diseases (e.g., retinal vein occlusion, age-related macular degeneration, etc.), neovascular glaucoma, previous vitrectomy, OCT image quality of $<6 / 10$; intraoperative complications such as posterior capsule rupture, vitreous loss, iridodialysis, and DM tear.

The following information were retrieved and analysed from the electronic medical records for patients fulfilling the inclusion and exclusion criteria. Demographic characteristics, duration of DM, other associated comorbidities like hypertension, presence or absence of dyslipidaemia, cardiovascular 
diseases, HbA1c levels, DR staging, details regarding prior treatment interventions in the form of intravitreal anti-VEGFs or intravitreal Dexamethasone implant or laser photocoagulation 5 months before the cataract surgery.

Visual acuity (log MAR), IOP, clinical grading of cataract using Wisconsin cataract grading system, Central subfield thickness (CST) and Total Macular Volume (TMV) using spectral domain optical coherence tomography (SD OCT) (Cirrus HD-OCT; Carl Zeiss Meditec, Dublin, CA) were reviewed at baseline,1 month, 3 months and 6 months following surgery.

CST was assessed using SD OCT of $512 \times 128$ scan pattern and $6 \times 6 \mathrm{~mm}$ scanning area centred on the fovea. CST and TMV were computed automatically by the inbuilt software in the SD OCT (Cirrus HD-OCT; Carl Zeiss Meditec, Dublin, CA).

Surgical procedure-patients who were divided into group 1 and group 2, both underwent a standard uncomplicated phacoemulsification technique with intraocular lens implantation in the bag. At the end of surgery, group 1 received either $0.05 \mathrm{ml}$ solution containing $1.25 \mathrm{mg}$ Bevacizumab or $0.5 \mathrm{mg}$ of ranibizumab and group 2 received $700 \mu \mathrm{g}$ of dexamethasone intravitreal implant (OZURDEX $\circledast$; Allergan, Inc., CA, USA) 3.5mm from the limbus through the pars plana. Both the groups received antibiotic -steroid combination in tapering doses for 6 weeks postoperatively.

Statistical analysis was performed using SPSS software (version 23.0; SPSS, Inc, Chicago, IL). Changes in the BCVA, CST and TMV were compared between the two groups using Mann-Whitney U test. Change in the Trend p for CST $(<300,300-600,>600$ microns) was calculated within each group using MannWhitney $\mathrm{U}$ test. $\mathrm{P}$ values $<0.05$ were considered statistically significant.

\section{Results}

Of the 56 patients, 36 patients had combined phacoemulsification and intravitreal anti-VEGF and 20 underwent combined phacoemulsification and intravitreal dexamethasone implantation and had a minimum of 6 months follow-up after the cataract surgery.

Table 1 demonstrates the baseline demographic characteristics of the study cohort. The mean age of group 1 and group 2 cohort was $62.31 \pm 11.39 y e a r s$ and $64.15 \pm 7.58$ years (mean \pm SD) respectively. The mean value of glycated haemoglobin (HbA1c) was found to be $7.2 \pm 1.37 \%$ and $6.7 \pm 0.92 \%$ in group 1 and group 2 respectively. 17 (47.2\%) of 36 and 2 (10\%) out of 20 had no prior intravitreal injection. 18 (50\%) of 36 and 7 (35\%) of 20 had no prior laser of any form. $9(25 \%)$ and $1(0.05 \%)$ of group 1 and group 2 neither were treatment naïve. The two groups were comparable in their baseline CST, TMV and BCVA. Mean IOP was 14.53 and $14.85 \mathrm{mmHg}$ in group 1 and group 2 respectively.

Table 2 shows the change in the mean CST, TMV and BCVA from baseline to 6 months follow up. Mean CST measured preoperatively at baseline were 382.46 $\pm 168.10 \mu \mathrm{m}$ and $419.35 \pm 234.27 \mu \mathrm{m}$ in group 1 and group 2 respectively. Although change in the mean CST from baseline to 1 month, 3 months and 6 months was found to be statistically insignificant, the greatest reduction was found at the 3 month period in group 1 (anti VEGF group) i.e,364. $29 \pm 147.43 \mu \mathrm{m}$ and at 1-month period in group 2 (dexamethasone implant group) i.e,382.95 $\pm 161.59 \mu \mathrm{m}$.

TMV was also found to be statistically insignificant from the baseline to 1, 3 and 6 months follow up period. BCVA showed improvement from baseline of log MAR $0.54 \pm 0.58$ to $0.49 \pm 0.57$ at 1-month period in group 1 cohort. Group 2 showed baseline BCVA of $0.43 \pm 0.34$ and $0.55 \pm 0.44$ at 6 months follow up with not much of visual improvement. Table 3 shows changes from baseline in CST, TMV and BCVA during the 6 months follow-up.

Table 4 shows proportion of patients who have received intravitreal injections in the postoperative period in both the groups. At 1-month period 14 out of 36 in group 1had anti-VEGF injections while none in the group 2 had any intervention. In group 1(Anti-VEGF) 17 had intravitreal anti-VEGF and 6 had dexamethasone implant at >1-3month period. Out of 20 in group 2 only 1 (due to the economic constraints of the patient) had intravitreal anti-VEGF while 8 eyes had additional intravitreal dexamethasone implant at >1-3month. At >3-6month period, 14 had anti-VEGF and 5 had steroid implantation in group 1 and 10 out of 20 in group 2 had repeat steroid implantation.

Table 5 shows proportion of patients whose Mean CST were divided into 3 groups of $<300 \mu \mathrm{m}, 300-600 \mu \mathrm{m}$ and $>600 \mu \mathrm{m}$. Out of 36 in group 1 , 14 ( $38.9 \%$ ) were in $<300 \mu \mathrm{m}, 17(47.2 \%)$ in $300-600 \mu \mathrm{m}$ and $5(13.9 \%)$ in $>600 \mu \mathrm{m}$. Out of 20 in group $2,8(40 \%)$ were in $<300 \mu \mathrm{m}, 7(35 \%)$ in $300-600 \mu \mathrm{m}$ and $5(25 \%)$ in $>600 \mu \mathrm{m}$.

Figure 1 shows change in the trend p value among mean CST groups of $<300 \mu \mathrm{m}, 300-600 \mu \mathrm{m}$ and $>600 \mu \mathrm{m}$. Statistically significant difference was found in mean CST<300 $\mu \mathrm{m}$ in both Anti-VEGF $(p=0.005)$ and Dexamethasone implant group $(p=0.018)$ from the baseline to the 6 months follow up period. $300-600 \mu m$ CST group showed no such statistical significance in either group whereas in the $>600 \mu \mathrm{m}$ mean CST group, there was significant statistical difference only in group 2(dexamethasone implant group) with $\mathrm{p}$ value of 0.043 .

Figure 2 shows change in the BCVA in the CST subgroups of $<300 \mu \mathrm{m}, 300-600 \mu \mathrm{m}$ and $>600 \mu \mathrm{m}$ in group 1 and group 2 . Although it was statistically insignificant, BCVA showed improvement in group 1(anti-VEGF) at 1 month and 3 months follow up in both $<300 \mu \mathrm{m}$ and $300-600 \mu \mathrm{m}$ subgroups.

\section{Discussion}

Uncomplicated Cataract surgery with CI-DME results in poor visual outcome. ${ }^{[7]}$ This may be attributable to both increase in VEGF levels which correlates with postoperative increase in CST at 1 month ${ }^{[8,9]}$, and also to a breakdown of the blood retinal barrier in response to the postoperative release of inflammatory mediators. ${ }^{[10]}$ 
In the present study, though both groups showed a reduction in mean CST at 6months, greater reduction was found at one month and at three months in group1(anti-VEGF group) and group 2 (dexamethasone implant) respectively. The baseline CST had a wide range of values 164-960 $\mu \mathrm{m}$ compared to any other published data till now. Hence, we subclassified the baseline CST values into $<300$ microns, $300-600$ microns and $>600$ microns and assessed change in $P$ value in these subgroups. Subgroups with $<300$ microns of CST, also received an intervention along with the cataract surgery as they were already receiving ongoing treatment either with an anti-VEGF or with the dexamethasone implant. There were significant differences in trend $p$ in $<300$ microns in both group 1 and group 2. 300-600 microns showed an increase in CST in both groups. In $>600$ microns, although both groups showed decrease in mean CST, there was significant reduction in group 2 over a 6 months follow-up $(p=0.043)$. We did not find statistically significant differences in terms of BCVA and also with no statistical heterogeneity between these two treatment arms at 6 months.

There was no significant difference in BCVA in any of these subgroups. The disparity between the CST and BCVA may be due to the chronicity of the DME and also the weak correlation shown to exist between CST and BCVA. ${ }^{[1]]}$ TMV also showed no significant difference instead a slight increase in both the groups in six months follow up period.

In contrast, many studies have shown that the mean CST decrease being is maximum at one month with the anti-VEGF group ${ }^{[12,13]}$ and 3 months in case of dexamethasone implant. ${ }^{[14]}$ Khodabandeh et al in their prospective randomized clinical trial which included 71 eyes from 71 diabetic patients randomized into two groups: combined phacoemulsification and intravitreal bevacizumab injection group and only phacoemulsification group, showed that bevacizumab group had lower CMT one month after the surgery compared to control group. Furino et al in their retrospective non randomized study of 16 patients showed reduction in the central retinal thickness (CRT) maximum at $30(120.5 \mu \mathrm{m})$ and 60 days $(160 \mu \mathrm{m})$ after the implant when the dexamethasone level is expected to reach its peak in the vitreous. ${ }^{[14]}$

Uncomplicated cataract surgery in pre-existing Diabetic macular edema (DME) causes disruption of blood retinal barrier and release of multiple inflammatory mediators such as VEGF, interleukin 6, protein kinase $C$ and results in endothelial dysfunction, leukocyte adhesion. This, results in increased vascular permeability and fluid accumulation within the macula. ${ }^{[19,20]}$

Anti-VEGF and Corticosteroids are the two main modalities used to treat CI-DME. ${ }^{[21]}$ Intravitreal anti-VEGF agents such as ranibizumab, bevacizumab, and aflibercept all have been used successfully to treat DME. Many Randomized clinical trials such as READ-2, RISE/RIDE, and RESTORE trials, have shown that ranibizumab is superior to macular laser whereas the BOLT trial demonstrated bevacizumab's superiority to laser. ${ }^{[22]} \mathrm{A}$ meta-analysis by Feng et collected six comparative studies and analyzed 283 eyes for the efficacy of intravitreal bevacizumab combined with cataract surgery in patients with diabetic retinopathy. They found that central macular thickness was significantly reduced at 1, 3 and 6 months postoperatively as compared to the control group. BCVA also showed significant improvement at 1 and 3 months follow up period whereas no such difference was found at 6 months. ${ }^{[15]}$

Some studies have shown improvement in visual acuity and reduction in central retinal thickness in patients with DME undergoing cataract surgery with antiVEGF agents ${ }^{[10]}$ While some prospective studies have shown no such improvement from baseline CRT values. ${ }^{[24]}$

Intravitreal dexamethasone implant used concurrently with the cataract surgery in patients with DME reduces the postoperative inflammation by two mechanisms, downregulating the VEGF and decrease of the inflammatory mediators thereby reducing the breakdown of blood retinal barrier system. ${ }^{[14,25]}$ Calvo et al studied twenty-four eyes of 24 patients in a prospective study followed up for 3 months. Intravitreal Dexamethasone implant was given at the end of the cataract surgery in diabetic retinopathy patients. They noticed a decrease in retinal thickness at 1 week, 1 month and 3 months postoperatively. The increase in CRT was less than 50 microns in all of the postoperative visits. BCVA also showed significant improvement in all 3 visits. ${ }^{\text {[16] }}$

In a study conducted by Corbelli et al where they compared combined versus 1 month deferred dexamethasone implant with the cataract surgery, they found no long-term difference in either anatomical or functional outcomes among the groups. They concluded that combined over deferred Dexamethasone implant was preferable as it showed protective effect from strong and acute inflammatory stimulus of cataract surgery and also reduces the number of hospital visits for the patient. ${ }^{[6]}$

Bressler et al in a prospective and non-comparative study, showed that more than half of the eyes who underwent cataract surgery with co-existing DME had no meaningful improvement of vision or worse along with definitive worsening in CRT. On the other hand, those who did not have diabetes gained $6 / 12$ or better vision in $>95 \%$ cases. ${ }^{[17,18]}$

However, anti-VEGF and dexamethasone delivery systems have different pharmacological properties and side-effect characteristics. Our study showed no significant adverse events such as rise in IOP or any infections (both ocular and systemic) postoperatively. Previous studies have also shown that Dexamethasone implant following cataract surgery shows no such increase in IOP and can be used safely. ${ }^{[26,27]}$

Ours being a retrospective study design, there were few limitations: (1) small sample size (2) short follow up period. (3) Heterogeneity due to the different group of anti-VEGF therapies. The DRCR.net Protocol T compared two-year results among the three anti VEGFs and found that intravitreal aflibercept, bevacizumab, and ranibizumab were all equally effective in visual acuity improvement and reduction in retinal thickness. ${ }^{\text {[23] }}$

The strength of the study is that both groups were comparative in their baseline demographic characteristics and mean CST and BCVA at the baseline. Even though there was a huge difference in baseline CST, this helped us to analyse the response of the treatment modality with three different sub-groups of CST values.

\section{Conclusion}


Our study demonstrates that individuals with CI-DME with lower baseline CST values undergoing combined phacoemulsification with either intravitreal AntiVEGF or Dexamethasone implant show similar anatomical and functional success at six months. However, eyes with higher baseline CST respond better anatomically to the Dexamethasone implant.

\section{References}

1. Kelkar A, Kelkar J, Mehta H, Amoaku W (2018) Cataract surgery in diabetes mellitus: A systematic review. Indian J Ophthalmol 66:1401-1410

2. Saeedi P, Petersohn I, Salpea P et al (2019) Global and regional diabetes prevalence estimates for 2019 and projections for 2030 and 2045 : Results from the International Diabetes Federation Diabetes Atlas, 9th edition. Diabetes Res Clin Pract. ; 157:107843

3. Liu J, Jones RE, Zhao J, Zhang J, Zhang F (2015) Influence of uncomplicated phacoemulsification on central macular thickness in diabetic patients: a meta-analysis. PLoS ONE 10:e0126343

4. Rashid S, Young LH (2010) Progression of diabetic retinopathy and maculopathy after phacoemulsification surgery. Int Ophthalmol Clin 50:155-166

5. Mukkamala L, Bhagat N, Zarbin MA (2017) Practical Lessons from Protocol I for the Management of Diabetic Macular Edema. Dev Ophthalmol 60:91108

6. Corbelli E, Fasce F, luliano L et al (2020) Cataract surgery with combined versus deferred intravitreal dexamethasone implant for diabetic macular edema: long-term outcomes from a real-world setting. Acta Diabetol 57:1193-1201

7. Hartnett ME, Tinkham N, Paynter L et al (2009) Aqueous vascular endothelial growth factor as a predictor of macular thickening following cataract surgery in patients with diabetes mellitus. Am J Ophthalmol 148:895-901e1

8. Stern AL, Taylor DM, Dalburg LA, Cosentino RT (1981) Pseudophakic cystoid maculopathy: a study of 50 cases. Ophthalmology 88:942-946

9. Qaum T, Xu Q, Joussen AM et al (2001) VEGF-initiated blood-retinal barrier breakdown in early diabetes. Invest Ophthalmol Vis Sci 42:2408-2413

10. Takamura Y, Kubo E, Akagi Y (2009) Analysis of the effect of intravitreal bevacizumab injection on diabetic macular edema after cataract surgery. Ophthalmology 116:1151-1157

11. Diabetic Retinopathy Clinical Research Network, Browning DJ, Glassman AR et al (2007) Relationship between optical coherence tomography-measured central retinal thickness and visual acuity in diabetic macular edema. Ophthalmology 114:525-536

12. Khodabandeh A, Fadaifard S, Abdollahi A et al (2018) Role of combined phacoemulsification and intravitreal injection of bevacizumab in prevention of postoperative macular edema in non-proliferative diabetic retinopathy. J Curr Ophthalmol 30:245-249 Published 2018 May 11

13. Chae JB, Joe SG, Yang SJ et al (2014) Effect of combined cataract surgery and ranibizumab injection in postoperative macular edema in nonproliferative diabetic retinopathy. Retina 34:149-156

14. Furino C, Boscia F, Niro A et al (2017) Combined Phacoemulsification and Intravitreal Dexamethasone Implant (Ozurdex®) in Diabetic Patients with Coexisting Cataract and Diabetic Macular Edema. J Ophthalmol 2017:4896036

15. Feng Y, Zhu S, Skiadaresi E et al (2019) Phacoemulsification Cataract Surgery with Prophylactic Intravitreal Bevacizumab for Patients with Coexisting Diabetic Retinopathy: A Meta-Analysis. Retina 39:1720-1731

16. Calvo P, Ferreras A, Al Adel F, Dangboon W, Brent MH (2018) Effect of An Intravitreal Dexamethasone Implant on Diabetic Macular Edema After Cataract Surgery. Retina 38:490-496

17. Lim LL, Morrison JL, Constantinou M et al (2016) Diabetic Macular Edema at the time of Cataract Surgery trial: a prospective, randomized clinical trial of intravitreous bevacizumab versus triamcinolone in patients with diabetic macular oedema at the time of cataract surgery - preliminary 6 month results. Clin Exp Ophthalmol 44:233-242

18. Diabetic Retinopathy Clinical Research Network Authors/Writing Committee, Bressler SB, Baker CW et al (2014) Pilot study of individuals with diabetic macular edema undergoing cataract surgery. JAMA Ophthalmol 132:224-226

19. Bhagat N, Grigorian RA, Tutela A, Zarbin MA (2009) Diabetic macular edema: pathogenesis and treatment. Surv Ophthalmol 54:1-32

20. Antcliff RJ, Marshall J (1999) The pathogenesis of edema in diabetic maculopathy. Semin Ophthalmol 14:223-232

21. Patelli F, Radice P, Giacomotti E (2014) Diabetic macular edema. Dev Ophthalmol 54:164-173

22. Lally DR, Shah CP, Heier JS (2016) Vascular endothelial growth factor and diabetic macular edema. Surv Ophthalmol 61:759-768

23. Wells JA, Glassman AR, Ayala AR et al (2016) Aflibercept, Bevacizumab, or Ranibizumab for Diabetic Macular Edema: Two-Year Results from a Comparative Effectiveness Randomized Clinical Trial. Ophthalmology 123:1351-1359

24. Rauen PI, Ribeiro JA, Almeida FP, Scott IU, Messias A, Jorge R (2012) Intravitreal injection of ranibizumab during cataract surgery in patients with diabetic macular edema. Retina 32:1799-1803

25. Wang K, Wang Y, Gao L, Li X, Li M, Guo J (2008) Dexamethasone inhibits leukocyte accumulation and vascular permeability in retina of streptozotocininduced diabetic rats via reducing vascular endothelial growth factor and intercellular adhesion molecule-1 expression. Biol Pharm Bull 31:1541-1546

26. Panozzo GA, Gusson E, Panozzo G, Dalla Mura G (2017) Dexamethasone intravitreal implant at the time of cataract surgery in eyes with diabetic macular edema. Eur J Ophthalmol 27:433-437

27. Sze AM, Luk FO, Yip TP, Lee GK, Chan CK (2015) Use of intravitreal dexamethasone implant in patients with cataract and macular edema undergoing phacoemulsification. Eur J Ophthalmol 25:168-172

\section{Tables}


Table-1: Demographic and clinical characteristics of our study sample ( $N=56$ eyes) at baseline

\begin{tabular}{|c|c|c|c|}
\hline Variables & & $\begin{array}{l}\text { Group } 1 \\
(\mathrm{~N}=36)\end{array}$ & $\begin{array}{l}\text { Group } 2 \\
(\mathrm{~N}=20)\end{array}$ \\
\hline Age (years, mean $\pm S D$ ) & & $62.31 \pm 11.39$ & $64.15 \pm 7.58$ \\
\hline Men & & $25(44.6 \%)$ & $14(25 \%)$ \\
\hline $\mathrm{HbA1c}(\%$, mean $\pm \mathrm{SD})$ & & $7.2 \pm 1.37$ & $6.7 \pm 0.92$ \\
\hline \multirow[t]{2}{*}{ Diabetic retinopathy status (N,\%) } & Non-proliferative & $22(39.3 \%)$ & $12(21.4 \%)$ \\
\hline & Proliferative(quiescent) & $14(25 \%)$ & $8(14.28 \%)$ \\
\hline Hypertension (N, \%) & & $17(30.3 \%)$ & $13(23.2 \%)$ \\
\hline Hyperlipidaemia (N, \%) & & $5(8.9 \%)$ & $2(3.6 \%)$ \\
\hline \multirow[t]{3}{*}{ Lens status ( $\mathrm{N}, \%)$} & Group 1(NS1+NS2) & $28(50 \%)$ & $12(21.4 \%)$ \\
\hline & Group 2(NS3+NS4) & $6(10.7 \%)$ & $4(0.07 \%)$ \\
\hline & $P S C$ & $2(0.03 \%)$ & $4(0.07 \%)$ \\
\hline \multirow[t]{3}{*}{ Previous intervention (N, \%) } & Intravitreal AntiVEGF & $8(14.3 \%)$ & $8(14.3 \%)$ \\
\hline & Intravitreal dexamethasone & $3(5.3 \%)$ & $13(23.2 \%)$ \\
\hline & Laser(Focal, PRP, Grid) & $18(32.1 \%)$ & $13(23.2 \%)$ \\
\hline Best corrected visual acuity & & $0.54 \pm 0.58$ & $0.43 \pm 0.34$ \\
\hline$(\log M A R$, mean $\pm S D)$ & & & \\
\hline Central subfield thickness & & $382.46 \pm 168.10$ & $419.35 \pm 234.27$ \\
\hline \multicolumn{4}{|l|}{$(\mu \mathrm{m}$, mean $\pm S D)$} \\
\hline Macular volume $\left(\mathrm{mm}^{3}\right.$, mean $\left.\pm \mathrm{SD}\right)$ & & $10.62 \pm 3.43$ & $10.19 \pm 4.1$ \\
\hline Intraocular pressure $(\mathrm{mmHg}$, mean $\pm \mathrm{SD})$ & & $14.53 \pm 4.84$ & $14.85 \pm 2.6$ \\
\hline
\end{tabular}

SD-Standard deviation, HbA1C-Glycated haemoglobin, NS-Nuclear sclerosis, PSC-Posterior subcapsular cataract, IVTA-Intravitreal triamcinolone, PRP-Pan retinal photocoagulation, log MAR-Logarithm of the minimum angle of resolution

Table 2: Mean CST, TMV and BCVA at each time point

\begin{tabular}{|c|c|c|c|c|c|c|c|c|c|}
\hline & & $\begin{array}{l}\text { CST (Mean } \pm \\
\text { SD) }\end{array}$ & & & & $\begin{array}{l}\text { TMV } \\
\text { (Mean } \pm \\
\text { SD) }\end{array}$ & & & \\
\hline & Baseline & 1 month & 3 months & 6 months & Baseline & 1 month & 3months & 6 months & Baseline \\
\hline $\begin{array}{l}\text { Group } \\
1\end{array}$ & $382.46 \pm 168.10$ & $401.49 \pm 137.52$ & $364.29 \pm 147.43$ & $398.06 \pm 169.29$ & $10.62 \pm 3.43$ & $11.19 \pm 2.47$ & $10.91 \pm 2.36$ & $11.21 \pm 2.3$ & $0.54 \pm 0.58$ \\
\hline $\begin{array}{l}\text { Group } \\
2\end{array}$ & $419.35 \pm 234.27$ & $382.95 \pm 161.59$ & $430.65 \pm 209.66$ & $467.85 \pm 214.61$ & $10.19 \pm 4.1$ & $10.92 \pm 2.77$ & $10.95 \pm 2.77$ & $11.71 \pm 2.35$ & $0.43 \pm 0.34$ \\
\hline $\begin{array}{l}\mathrm{P} \\
\text { Value }\end{array}$ & 0.793 & 0.436 & 0.223 & 0.326 & 0.752 & 0.842 & 0.790 & 0.477 & 0.803 \\
\hline
\end{tabular}


Table 3: Mean Change in CST, TMV and BCVA from the baseline

CST (Mean \pm SD)

TMV (Mean \pm SD)

BCVA (Mean \pm SD)

$\begin{array}{lllllllll}1 \text { Month } & \text { 3 Months } & 6 \text { Months } & 1 \text { Month } & 3 \text { Months } & 6 \text { Months } & 1 \text { Month } & 3 \text { Months } & 6 \text { Months } \\ -26.17 \pm 99.53 & -2.77 \pm 152.91 & -33.17 \pm 219.74 & -0.06 \pm 1.38 & 0.22 \pm 1.56 & -0.29 \pm 1.75 & 0.05 \pm 0.23 & 0.04 \pm 0.35 & 0.01 \pm 0.37 \\ 36.4 \pm 177.27 & -11.3 \pm 223.23 & -48.5 \pm 208.58 & -0.19 \pm 3.45 & 0.32 \pm 2.50 & -0.45 \pm 2.54 & -0.02 \pm 0.35 & -0.14 \pm 0.4 & -0.12 \pm 0.39 \\ 0.820 & & & & & & & & \\ & 0.834 & 0.909 & 0.19 & 0.49 & 0.71 & 0.53 & 0.36\end{array}$

CST-Central subfield thickness, TMV-Total macular volume, BCVA-Best corrected visual acuity, VEGF-Vascular endothelial growth factor, SD-Standard Deviation

Table 4: Proportion of patients who received Intravitreal injections postoperatively

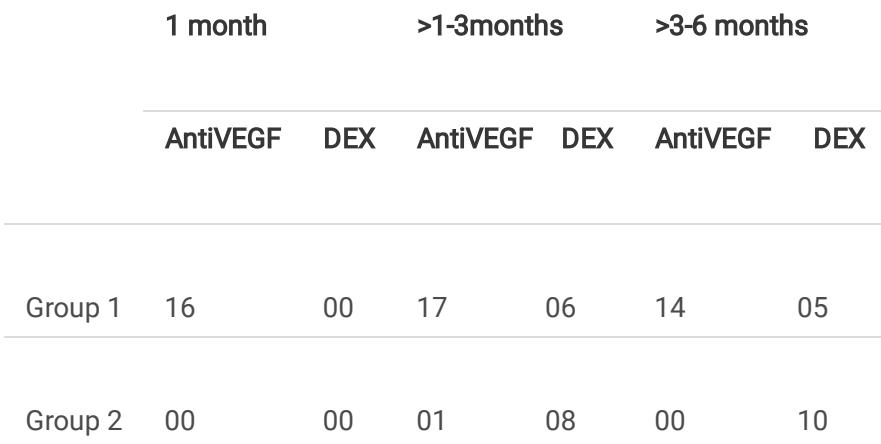

VEGF-Vascular endothelial growth factor, DEX-Dexamethasone implant

Table 5: Proportion of patients whose mean CST were subclassified into $<300,300-600$ and $>600$ microns

CST in microns

\begin{tabular}{llll}
\hline & $<300$ & $300-600$ & $>600$ \\
\hline Group 1 & $14(38.9 \%)$ & $17(47.2 \%)$ & $5(13.9 \%)$ \\
\hline Group 2 & $8(40 \%)$ & $7(35 \%)$ & $5(25 \%)$ \\
\hline P value & 0.935 & 0.376 & 0.298
\end{tabular}

CST-Central subfield thickness, VEGF-Vascular endothelial growth factor.

\section{Figures}




\section{FIGURE:1}
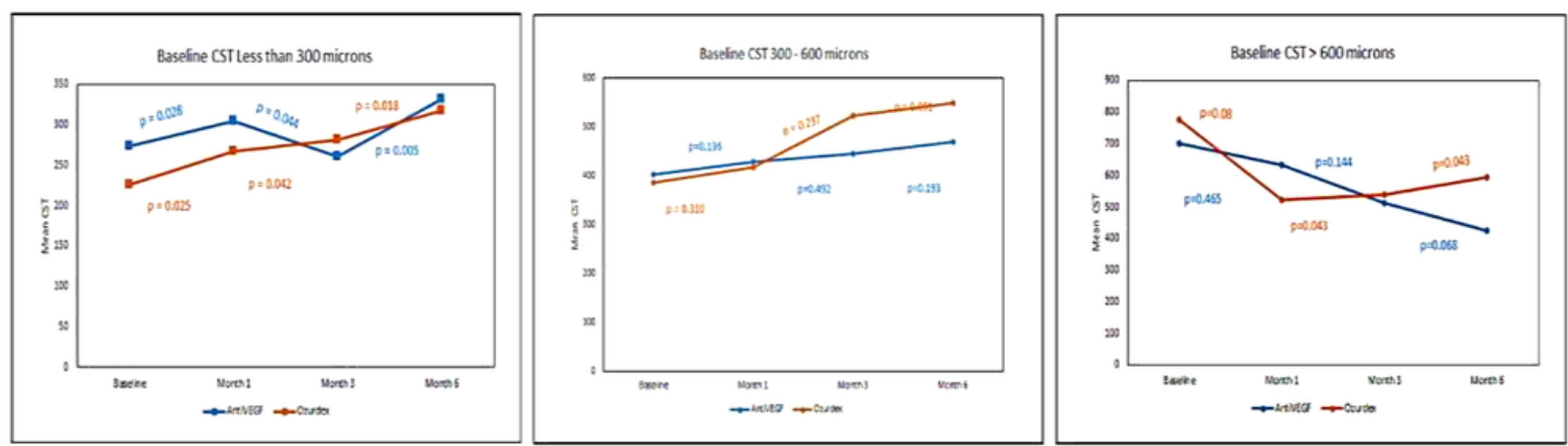

Figure 1:Line graph showing CST in subgroups of $<300$ microns, 300-600 microns and $>600$ microns

\section{Figure 1}

Line graph showing CST in subgroups of $<300$ microns, 300-600

microns, > 600 microns. 


\section{FIGURE:2}
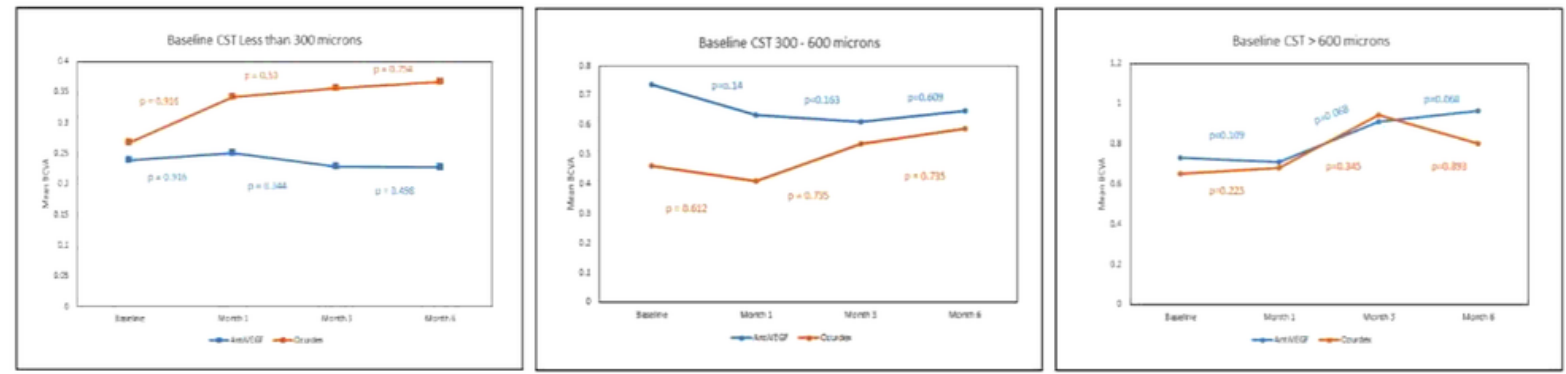

Figure 2:Line graph showing BCVA in subgroups of $<300$ microns, $300-600$ microns and $>600$ microns

\section{Figure 2}

Line graph showing BCVA in subgroups of $<300$ microns, $300-600$

microns, > 600 microns. 